\title{
Outsourcing information systems: drawing lessons from a banking case study
}

\author{
LP Baldwin ${ }^{1}, \mathrm{Z} \mathrm{Irani}^{1}$ and PED Love ${ }^{2}$ \\ ${ }^{1}$ Department of Information Systems and Computing, Brunel University, Uxbridge, Middlesex, UB8 3PH, UK; ${ }^{2}$ School of \\ Architecture and Building, Deakin University, Geelong, Victoria, 3217 Australia
}

\begin{abstract}
Financial and costs benefits are often put forward as the reasons why organisations decide to outsource. Emerging patterns and trends indicate that today's outsourcing decisions are often motivated by factors other than cost. Thus, the decision-making process is more complex than it may at first appear. This paper presents findings from a case study from an organisation in the UK banking sector that was motivated to outsource aspects of its information technology/information system (IT/IS). The underlying motives and decision-making process that influenced the bank outsource its IT/IS are presented and discussed. Findings from the case study suggest political perspectives, as well as human and organisational issues influenced the bank's strategic decision-making to outsource certain aspects of its business. An examination of the case study findings suggests that cost alone is not always responsible for decisions to outsource, as it was found the bank's outsourcing decision was driven by a series of complex, interrelated motives in a bid to reduce the risks and uncertainties of managing its own technology. Considering the complex nature of the outsourcing process a frame of reference that can be used to assist managers with their decision to outsource IT/IS is propagated. The case study is used to present an organisation's experiences as to how and why it decided to outsource its IS and thus offers a learning opportunity for other organisations facing similar difficulties. In addition, the case study findings highlight the need to focus greater attention on discriminating between the short and long-term consequences of IT/IS decision-making. European Journal of Information Systems (2001) 10, 15-24.
\end{abstract}

\section{Introduction}

The decision to insource or outsource, that is, whether to make in-house or to buy from external sources, has never been an easy task for those involved in the decision-making process (Yang \& Huang, 2000). The reason for this is that it involves considerable complexity and business risks (Cronk \& Sharp, 1995; Antonucci \& Tucker, 1998; Marcolin \& McClellan, 1998). In the case of Information Technology/Information Systems (IT/IS), outsourcing concerns turn over all or part of an organisation's IS operations to outside contractors (O'Brien, 1996; Yang \& Huang, 2000). Benefits of outsourcing are cited as including reduced costs, better service and access to new technology, as well as enabling staff to focus their efforts on higher-value work thus improving output (Ketler \& Walstrom, 1998; Lacity \& Willcocks, 1998; Quinn, 1999). As organisations strive towards greater competitiveness, flexibility and to improve their overall performance, emphasis has shifted from other (non-core) corporate activities to greater focus on business processes likely to bring competitive advantage (Ngwenyama \& Bryson, 1999; Quinn, 1999). Outsourcing is thus increasingly seen as a strategy that can be used by organisations to leverage skills and com- petencies of a definable pre-eminence. Consequently, organisations are able to choose to outsource activities for which they do not have a critical need, or for which they lack the special capabilities to do themselves (Quinn \& Hilmer, 1994).

Since the early 1990s, there has been a significant increase in the number of organisations that have decided to outsource all or some aspects of their IT/IS functions. As a result, research into IT/IS outsourcing has proliferated (eg Loh \& Venkatraman, 1992; Lacity \& Hirschheim, 1993; Currie \& Wilcocks, 1997; Duncan, 1998; Quinn, 1999; Currie, 2000). While such research has enabled some organisations to better understand the processes of decision-making and the consequences of outsourcing, it is not useful for all, as organisations have their own unique circumstances. Given this, there is always a need to gain insights into how and why organisations decide to outsource so that others can learn from their experiences. To develop an understanding of how and why organisations choose to outsource, it is necessary to seek explanations for the underlying motives behind these decisions (Ketler \& Walstrom, 1993; Fink \& Shoeib, 1998; Willcocks \& Kern, 1998).

According to Fowler and Jeffs (1998), the growing popularity of outsourcing suggests that there is a need 
to gain an understanding about financial and political factors that managers take into account when deciding to outsource IT/IS functions. Hirschheim and Lacity (2000) suggest that decisions about outsourcing relate not only to financial factors but also that socio-technical factors play a part in the decision-making process. They conclude that without an understanding of the different stakeholder perspectives of those involved in the process, measuring the success or otherwise of outsourcing is neither possible nor worthwhile. The research reported in this paper suggests that organisations need also to focus on the risks and benefits in the short and long term if they are to gain a sustainable competitive advantage in their respective marketplaces. The past, present and future trends of outsourcing in the European context are presented. This is followed by a description of the research methodology. The case study organisation's financial stability, major strategies and the traditional role of IT/IS within the organisation are then described. The decision-making processes associated with outsourcing IT/IS functions and their life cycle are then presented and discussed. A frame of reference that other organisations can use as a guide to the outsourcing decision-making process is proposed. The case study is used to present an organisation's experiences as to how and why it decided to outsource its IS and thus offers a learning opportunity for other organisations facing similar difficulties. In addition, the case study findings highlight the need to focus greater attention on discriminating between the short and long-term consequences of IT/IS decision-making.

\section{Outsourcing trends: a European perspective}

The outsourcing market in Western Europe has grown enormously since the early 1990s. A recent survey (IDC, 1998) indicates that worldwide spending on outsourcing services reached $\$ 86$ billion in 1996 and is expected to surpass $\$ 136.6$ billion by 2001 . In terms of the outsourcing market in Western Europe, this is predicted to increase to US $\$ 33.6$ billion by 2001 , a figure representing approximately $26 \%$ of the global outsourcing market (Currie, 1998). The UK remains one of the most mature outsourcing markets, and closest to the US in terms of market dynamics. Collins (1998) suggests that by $2000,75 \%$ of UK enterprises will outsource aspects of their business, although it is still too early to say whether this has been realised. This trend is expected to increase, with outsourcing of operations, maintenance and application development forcing a reduction of staff levels in IT/IS departments. Table 1 presents the expected growth in the market from 1996-2001.

Emerging business drivers for outsourcing continue to manifest themselves, and include shortage of skilled human capital, privatisation and deregulation pressures,
Table 1 Worldwide and European outsourcing market spending 1996 and 2001 (\$ million)

\begin{tabular}{lcc}
\hline & Worldwide & $\begin{array}{c}\text { Western } \\
\text { Europe }\end{array}$ \\
\hline 1996 & 86096 & 22666 \\
2001 & 136601 & 33616 \\
CAGR 1996-2001 & $9.7 \%$ & $8.2 \%$ \\
\hline
\end{tabular}

Source: International Data Corporation, 1998.

emerging technologies such as the Internet, the adaptation to the European Monetary Union (EMU), structural changes in the value chain and government institution budget costs. European companies are becoming increasingly competitive and as a result many are beginning to outsource many of their business functions. In addition, government privatisation, public sector budget cuts and industry deregulation are all pan-European business issues that are driving the increasing demand for outsourcing services. When outsourcing service types are compared, Business Process Outsourcing (BPO) is the most popular form in Europe (Currie, 1998). European BPO market spending is projected to grow at a Compound Annual Growth Rate (CAGR) of $22.8 \%$ by 2001. Promising areas for BPO in Europe are considered to be administration, accounting, human resources, logistics and customer services. As noted in Table 1 the IT/IS outsourcing market is projected to grow at a CAGR of $9.5 \%$ by 2001 , and the processing services market at a CAGR of $6.6 \%$.

In Europe, selective outsourcing is gaining in popularity. Most outsourcing contracts are still based on fixed price arrangements however providers are increasingly expecting to work with risk/reward components in their deals. This is particularly so when the agreement contains a significant element of high-value services, such as business consulting.

\section{Outsourcing functions}

The type of IT/IS functions that companies are choosing to outsource continues to both change and develop. Currently in the UK, IT/IS operations dominate the outsourcing market, with hardware maintenance as the most outsourced service (about 70\%), followed by mainframe or data centre management (38\%), and PC support, network management $(25 \%)$. According to Currie (1998), the percentage breakdown of IT/IS services in the UK over the next four years will be $25 \%$ desktop/distributed; $18 \%$ applications; $15 \%$ networks and $42 \%$ data-centres. Desktop outsourcing or desktop managed services is a highly cost-driven and commodity-like segment that is increasingly addressed by both international and local vendors. Business process outsourcing remains increasingly popular in the European outsourcing market; how- 
ever, for the most part, this market is still relatively new. The capabilities and expertise needed to address this market are quite different from traditional IT/IS outsourcing as BPO involves a substantial component of non-IT/IS activities and, accordingly, the transfer of nonIT/IS staff. Outsourcing of IT/IS is currently a pan-European phenomenon as organisations face pressures due to global competition, deregulation, technological innovation and public sector budget cuts. It would also appear that the IT/IS outsourcing phenomenon is being embraced by organisations in other continents such as Southeast Asia as they too seek to become more competitive and flexible in their business operations (Yang \& Huang, 2000).

\section{Research methodology}

The research methodology used to conduct this study is one that is divided into three phases, that is: research design; data collection; and data analysis. The first stage in the methodology is the research design phase, which involved a review of the literature on outsourcing and decision-making. The identification and development of a suitable research strategy and method then followed this (Yin, 1994). The strategy adopted during this enquiry was that of a single fieldwork case study (Yin, 1994). A fieldwork case study can be used to collect both quantitative and qualitative data (Weick, 1984), but as the objective of the case study was to discover how and why the organisation chose to outsource, a qualitative approach was adopted. Data were gathered primarily by way of a semi-structured questionnaire that served as an interview agenda during the interviewing of managers and directors. This enabled the researcher to steer the interview process. All interviews were tape recorded and later transcribed to ensure accuracy and reliability. These were then given back to each person who had been interviewed to check and resolve any discrepancies that may have arisen and thus to eliminate any interviewer bias. Bearing in mind the scope and large amount of evidence gathered, scrupulous attention was paid to ensuring that the data collected converged on similar facts (Jick, 1979).

\section{Case study background}

The organisation used in the case study is a major UK bank forming part of a banking conglomerate. This case study organisation outsourced a chain of IS functions to several vendors. This was one of the first and largest contracts in their outsourcing history. The contract involved paying over $£ 100$ million to a major telecommunications company to handle its voice and data communication functions.

Outsourcing was first evaluated in this organisation in 1990, when the outsourcing market in the UK was embryonic. The decision to outsource was initiated by the Head of Group IT and gained the strong support and commitment from the Managing Director. The bank offers consumer and commercial banking at more than 1700 locations throughout the UK and Ireland, and employs more than 77000 people. Its domestic affiliates offer mortgage banking, retail brokerage, financing, and leasing services. To refocus on its core UK business, the company sold its international investment-banking unit, and merged several units, including private banking for the wealthy, into a wealth management service. The organisation is not only a premier commercial bank but it is also one of the most innovative personal banks, as well as being a major provider of wealth management products to personal and corporate clients. The bank is also a key provider of card products and services, and is a leading participant in the world of electronic commerce banking. The organisation enjoys firm financial stability and has made significant progress over the last few years in repositioning its business and improving its overall strategic focus. It is now a unified organisation that provides a broad spectrum of financial services to customers ranging from individuals and small businesses to multinational companies. Investment in IT/IS plays a vital role in the strategy of the bank with the IT/IS operations budget in 1998 totalling $£ 260 \mathrm{~m}$; it maintains a large IS department of about 1000 employees. Further IT/IS investments are already earmarked as part of its longterm strategic business plan.

The banking and financial services industry in the UK has become extremely competitive, as the numbers of financial institutions have multiplied exponentially over the last few years. The reasons for this are considered complex and thus are not within the scope of this paper. However, customers these days are increasingly likely to choose to take their custom away from the traditional high street banks (the so-called 'bricks and mortar' banks) and to instead do business with banks that offer services either by post or over the Internet (so-called 'clicks and mortar' banks). The traditional 'bricks and mortar' banks can no longer rely on keeping customers by claiming that they offer a more personal service, as it appears that customers today are prepared to trade this in for the higher interest rates, and easier access, offered by postal or Internet banking. In demonstrating this point, a business planning bank manager at the case study organisation stated:

\begin{abstract}
'The UK is highly 'overbanked' (and) it has become very crucial to provide, unique, value-added, high quality banking services to stay in business or be competitive. IT helps us maintain our advantage and is integral to our success.'
\end{abstract}

This emphasises one of the organisation's main strategies, that is, to provide competitive, high quality, value-added banking services to its clients. For the past few years the organisation's policy, which is set out in 
its mission statement, has been to become more competitive. IT/IS is very closely linked to their business strategy and thus forms an integral part of the company infrastructure. The traditional role of the IT/IS department is not merely a utility but is instead seen as a core part of the organisation that facilitates the bank in providing competitive banking services. IT/IS is seen as a mechanism that supports and drives their business strategy. To better understand the basis of the decision to outsource, it is important to understand the relationship between outsourcing evaluations and the views of senior management towards IT/IS within the organisation, as Hirshheim and Lacity (2000) readily agree.

\section{Decision-making structure}

The IT/IS department is highly regarded within the organisation. The placement of the IT/IS department within the corporate structure is seen as a major indicator of the importance attached to IT within the organisation. The director of Group IT/IS is a rank below that of the CEO and reports directly to him. Analysis of the data gathered by way of interviews suggests that there is strong top management support for IT/IS within the bank. As in any business agreement between two or more organisations, the legally binding contract plays its role in the outsourcing process. The bank's outsourcing contract was signed in the early days of outsourcing, when relationships between the client and vendor were viewed more in terms of a game (or perhaps adversarial in nature), with each party wanting to be the winner. In this case, the bank seemed to be the winner whilst the communications vendor assumed the initial loss leader position and thus profited from the contract in the longterm. The contract that was signed was a fixed plus management fee type. This type of contract involves a fee based on the actual costs of providing a service or facility (calculated on a periodic basis over the life of the contract) plus a management fee. The structure of this contract is rigid, and is in contrast to the more flexible and beneficial risk/reward contracts currently in use. These days contracts are designed to ensure better performance via controls such as defined service level agreements, effective benchmarking incentive schemes and fines for poor delivery and performance. In fact, it would appear that many contracts go some way towards reducing the threat of opportunism as outsourcing is geared towards partnership, or co-sourcing (more popularly known as a strategic alliance), where parties work together in a relationship to achieve their objectives.

\section{Outsourcing lifecycle}

The bank's outsourcing lifecycle spans from the period 1990 to 1999, and its six phases are outlined in Table 2.

The Director of Group IT/IS was the first to suggest that outsourcing should be considered, which was subsequently investigated by an IT/IS Strategy and Policy team. The IT/IS Operations Group then reviewed and investigated the outsourcing options. Once reviewed the necessary formal analyses were undertaken and recommendations were then passed back to the IT/IS Strategy and Policy team. The Strategy and Policy team then fed information back to the Director of Group IT/IS who presented a report to the Managing Director. The Managing Director then handed a comprehensive evaluation report to the Group Purchasing Department. The process ended at the desk of the Managing Director, where it was sanctioned for implementation. The initial evaluation was presented to a 20-member Bank Board (consisting of mainly senior managers/executives) merely for approval, in line with normal capital budgeting company policy. The complete outsourcing transaction involved over $£ 100 \mathrm{~m}$ and constituted $60 \%$ of the $£ 260 \mathrm{~m}$ IT/IS operations budget. Other active employees in the above process raised concerns about the risks involved and were in favour of keeping telecommunications activities in-house, that is to say, not to outsource and lose strategic and operational control. The final decision was eventually made after evaluating outsourcing through a formal feasibility analysis. Having made the decision to outsource, the bank needed to evaluate the benefits of outsourcing for the long term. The following section looks at how the bank arrived at its outsourcing decision.

\section{Benefits and drawbacks of outsourcing}

The bank's approach to assessing the impact of its outsourcing decision has been one of continuous evaluation. The estimated costs for the contract at the time of writing were $£ 100 \mathrm{~m}$. However, it was difficult to make benefit comparisons as these were largely considered to be nonfinancial and intangible in nature. Consequently, the bank chose not to use the amount of money saved as a measure of benefit achieved but instead decided to allow other, as yet unpredicted, benefits to unfold as the project progressed. This reflects a consideration for not only the short term but the long term as well. In addition, this suggests that the bank was more interested in other benefits of outsourcing rather than financial implications, and therefore chose not to make a meaningful and formal financial analysis to justify its outsourcing. A response from an interviewee indicated that an overall postimplementation evaluation was planned to take place at the end of the contract, which meant the prospect of not only renewing the contract but also analysing the success of the outsourcing decision. Those in the organisation encouraged and promoted the notion that learning from previous project successes and failures was a vital part in the development of the bank. In retrospect, it appeared that the bank's intention to outsource was not governed 
Table 2 Six phases of the bank's outsourcing lifecycle

\section{Phase 1}

The company started evaluating outsourcing as early as 1990 when the UK outsourcing market was immature and undefined. In 1990, the deregulation of the telecommunications industry prompted top management to investigate the feasibility of outsourcing, hoping to have access to high and quality service levels from a more competitive telecommunications market. However the market at the time was made up of a big and monopolistic telecommunications company and a host of small other companies and as such, the market was considered risky and not competitive.

\section{Phase 2}

In 1992, outsourcing was reconsidered, but the market was still too immature, risky and not competitive enough. The telecommunications market had not changed considerably; it was still risky, immature and dominated by a large company. As a result the organisation shelved its outsourcing plan.

\section{Phase 3}

In 1993, however, the organisation took the bold step to re-evaluate outsourcing to identify its main objectives, having made extensive and rigid feasibility studies. The bank at this time saw the market good enough to outsource even though the range of vendors was not large enough. The objectives identified were mainly to (in order of priority):

- Escape from a legacy system. The bank resorted to outsourcing to avoid the burden and risks of migrating from a legacy system to a modern up-to-date telecommunications system and thus focus on core business activities where their capabilities lay.

- To handle the year 2000 problem. As far back as 1992, the bank saw the need and urgency to tackle year 2000 compliance problem. Outsourcing provided the opportunity to deal with this burdensome problem, by shifting the risks and complexities onto the telecommunications company who were better equipped to handle this problem.

- To gain access to new technology. As mentioned earlier outsourcing provided the chance for the bank to have access to a wide range of new telecommunication technologies including voice service delivery and high speed bandwidth. This was deemed necessary to provide a unique, competitive and high quality banking service to clients.

- To optimise the use of telecommunication by transferring fixed costs to variable cost (that is, pay as you use). Outsourcing telecommunications services enabled the bank to switch to a pay-as-used mode by sharing telecommunications facilities. This implied using the optimum capacity of telecommunication facilities, and was made possible by transferring fixed telecommunications costs into variable costs. This was purely to eliminate or reduce cost inefficiencies, to curb expenditure on telecommunications.

\section{Phase 4}

The evaluation period lasted for 2 years before the contract was finally signed in 1995. This stage involved an extensive, thorough and rigid feasibility study before a decision was made and the plan put to action after senior management approval.

\section{Phase 5}

This marked the transition period, when all the bank's voice and data communications activities were handed over to the telecommunications company. Once the bank made the decision to outsource, the preferred vendor was called in and implementation began.

\section{Phase 6}

This is the period when the telecommunications company took over fully and started the live running. At this stage they were fully in charge and owned all telecommunications assets within the bank; implementation of outsourcing was in full swing.

by motives of financial gain. Instead, there was evidence of a more business-wide intent, with strategic and tactical implications taking precedence.

Nearly three years after the decision to outsource, the organisation appeared to have achieved nearly all of its pre-planned objectives for outsourcing aspects of its voice and telecommunications facilities, which focused on:

- a successful migration from a legacy system to a technology;

- ensuring the implementation of Enterprise Application Integration was achieved and that data pools and historic information were effectively used;

- addressing the $\mathrm{Y} 2 \mathrm{~K}$ problem;

- hardware and software audit;
- reducing cost inefficiencies; and

- improving access to new telecommunications technology.

The senior manager of technology planning for IT stated that:

'Outsourcing has been successful ... we are fairly satisfied with the deal. We have transferred our burdensome IT tasks and risks such as the legacy problem and the year 2000 problem over to the vendor. We have also optimised our uses of telecommunication by adopting a 'pay as used' approach ... by sharing data communication resources. This has allowed us to transfer our fixed (telecommunication) costs to variable costs.' 
The senior manager of technology also expressed concern over the unsatisfactory levels of technology access and the escalating indirect costs and spending on telecommunications. The direct costs included initial hardware costs (on telecommunication equipment), initial software costs, including networking software, installation and configurations costs including management consultancy support networking costs, network wiring junction and connector maintenance costs. Others include unexpected hardware costs due to upgrades, and familiarisation courses. The standard of technology expected by the company in voice service delivery and high-speed bandwidth were not, in the view of the bank, what the communications vendor provided. The cost of voice communication had sharply risen and it was projected to exceed the $£ 100 \mathrm{~m}$ mark by the end of 1999 . Data communications costs have fluctuated over the years but are now increasing slightly. One of the interviewees stressed that even though telecommunication costs had escalated sharply, it was still better to outsource their telecommunications services than resource and build in-house. The organisation's outsourcing decision was not influenced by financial savings but still remained to be internally judged by management as a success. However, as discussed above, the savings that resulted from outsourcing were not measured in financial terms and given the nature of the benefits stated were readily quantifiable. It is therefore not possible to analyse the success of the outsourcing decision. Moreover, outsourcing benefits, as with any benefit in IT/IS take time to filter down through the organisation. With this in mind not all the consequences of outsourcing can be evaluated in the short-run.

\section{Risk averse organisational culture}

The bank has cultivated a risk-averse policy and as a result saw outsourcing as a vehicle for transferring the risks associated with IT/IS to a vendor. The risk-averse culture of the bank was reflected in its decision not to outsource (or outsource a very small portion of) their IT/IS services including security, architecture/design, maintenance and strategic planning.

However, the bank decided to outsource other IT/IS business functions, which included applications development, operations, disaster recovery, communications and asset management. The interpretation of the decisionmakers' actions reflected the bank's business-wide intents and aims. Being in a competitive informationintensive business, it was the aim of the bank to provide a competitive banking service using up-to-date technology. However, technology was changing too quickly for the bank to ensure that they had not only the most up to date technology available but also a responsive infrastructure. Moreover, both internal and external customers seemed to be inadequately served by the existing (legacy) system. The bank was well aware that it had to update its technology, and that this would necessarily involve not only the migration from a legacy system to an enterprise-wide solution, but also tackling the Y2K problem. Given the complexities and uncertainties surrounding these two activities and the risk-averse culture of the organisation, it was considered reasonable to resort to outsourcing rather than handle them in-house.

The IT/IS vendor that was eventually selected was judged to be better experienced and capable in achieving the identified business objectives than the bank itself and was thus assigned this task. The intent of gaining access to new technologies was considered a reasonable motive for deciding to outsource. Regardless of a mature and capable IS department, its IT capabilities were not strong enough to handle rapidly changing and sophisticated telecommunications services. The organisation had to leverage their resources into other IT (and business) activities where their (seemingly better) capabilities lay, as well as retaining their focus on core business. Outsourcing therefore presented the bank with an ideal opportunity to gain access to new telecommunication technologies, while at the same time lessening the risk involved in trying to manage the approach in-house. Access to technologies such as high speed bandwidth and voice service delivery, delivered by the IT vendor, fell short of the agreed service level that the bank had expected, with the Manager of Business Planning and Performance stating:

\begin{abstract}
'Some members of the decision-making group, particularly some Group IT members, were concerned about risks associated with outsourcing and expressed the opinion of building and acquiring new technologies as well as handling complex activities such as the legacy and year 2000 problem in-house.'
\end{abstract}

\section{Politics and risks of outsourcing}

The risk-averse stance taken by the decision-makers towards the issue of $\mathrm{Y} 2 \mathrm{~K}$ compliance and the migration from a legacy telecommunication system were the main factors influencing the decision of whether to outsource. After considering the risks associated with outsourcing aspects of the IT/IS as well as those risks involved in maintaining the infrastructure in-house, it was eventually decided to outsource and the contract was signed. However, the decision was taken in the embryonic stage of outsourcing. Hence precipitating factors appear to indicate that the decision to outsource, with intent to optimise the use of telecommunications service, was influenced in part by political and financial motives. However, a more business-wide intent began to also unfold and thus the perceived benefits of outsourcing to the organisation as a whole were seen to influence the 
bank's decision to outsource; political and financial motives played a more minor role.

The bank outsourced what both senior management and more junior staff considered to be high-risk, everchanging and complex IT functions, all of which formed an essential part of the business. Despite this, the organisation also managed to maintain a degree of control over its telecommunications function. Findings from the interviews suggested, however, that some managers and employees expressed some regret from outsourcing too early, at a time when the market was in its infancy. This was expressed in a statement by one of the managers, who commented that:

'We probably outsourced too soon when the market was undefined and not competitive enough.'

This statement also reflects their concern for high telecommunications costs (mainly due to the use of expensive modern technology). Even though they expressed this opinion, they also agreed that providing their data communications service in-house would have cost much more, and taken more time.

It appears that many intentions, or business benefits, that underlie the decision to outsource may not impact on organisations for several years. In the case of the bank, outsourcing may indeed not make an impact until beyond 2001. The outsourcing of data communications within the bank was found to have profound effects on its expenditure in the short term due to the high initial costs in communications technology but this may not be the case in the long term. Indeed, from the senior management perspective, outsourcing benefits were claimed to outweigh the disadvantages/dis-benefits. The avoidance of risks and (some) access to technology far outweighed the short-term problem of escalating data communications costs. For the bank, then, it would seem that the main reason to outsource, though not explicitly stated, related to the risk allocation, that is, to share the risk between the bank and the outsourcing providers. As a risk-averse organisation, outsourcing was seen as a way of offloading some of the responsibility (that is, risk) onto the outsourcing providers. The identification and management of risks associated with outsourcing is a recurrent theme for almost all businesses who decide to outsource. There is currently a growing number of selective outsourcing contracts with multiple vendors, and many of these contracts are short term in nature.

\section{Implications for outsourcing decision- making}

A selective sourcing approach using multiple suppliers is an increasingly popular strategy to minimise risks, maximise benefits and reduce costs (Lacity \& Hirschheim, 1993; Fitzgerald \& Willcocks, 1994; Currie,
1996, 1998; Currie \& Willcocks, 1997). Those who outsource wisely and carefully stand to gain lasting valueadded benefits from outsourcing. Indeed, the interviewees in the bank identify a number of benefits similar to those suggested by Lacity and Willcocks (1998). Such benefits are summarised to include:

- standardisation of functional processes;

- automation of business processes;

- effectively deployed resources;

- better charge-back systems to recover capital;

- consolidation of dispersed processes or departments;

- departmental reorganisation and restructuring;

- employee empowerment;

- just-in-time resources;

- more efficient resource usage;

- service elimination;

- tougher hardware and software negotiations;

- service level agreements;

- software standardisation;

- increased efficiency and effectiveness; and

- reduced costs from vendors and suppliers based on economies of scale.

Organisations involved in outsourcing decisions need to be aware that certain resulting benefits from outsourcing may be short-lived given the rapid change in technology. It might therefore be reasonable to outsource certain non-key IT/IS functions while retaining the expertise to develop strategic information architecture, and a suite of strategic systems that are capable of delivering competitive advantage. However, careful consideration of the implications resulting from the longterm loss of expertise and a periodic re-visit of the sophisticated notion of core competencies/business needs should be factored into the strategic and tactical planning. Consideration must also be given to a rigid assessment of potential future key success factors and a realistic assessment of the new opportunities/problems that outsourcing is likely to create, as well as the alternatives to outsourcing available. The benefits and risks associated with the short and long term affect businesses in different ways, with scenario planning being a strategic planning tool for analysis (Schoemaker, 1995). The management of risk will similarly need to take account of these differences, and to this date this aspect has been given limited attention in the IT/IS literature. This is particularly important given the increasing incidence of outsourcing in Europe, which involves multiple vendors in short-term and long-term contracts. Risks arising from contracts with multiple vendors with the bank included:

- competition between vendors which can be detrimental to the client;

- breakdown of IT/IS department to be replaced with project management department;

- difficulty in managing multiple suppliers, each with their own agendas and each wanting to increase their business with the client; 
Table 3 Factors to be taken into account when considering outsourcing

Use of internal staff rather than external consultants

Use internal staff as much as possible rather than employ the expensive services of external consultants during outsourcing.

\section{Internal preparations}

Use internal staff (where possible) to prepare or 'clean up' the organisation before handing over to vendors. Using the vendors to do this increases the outsourcing bill.

\section{Post-implementation evaluation}

Carry this out to assess the benefits and true costs of outsourcing.

\section{Monitor contractors and enforce control mechanisms Use control mechanisms such as performance fines, incentives, service level agreements, effective benchmarking to reduce opportunism. Monitor progress to ensure quality service from vendors.}

\section{Analyse and scrutinise outsourcing critically} When considering outsourcing, look out for hidden and internal factors. Outsourcing should be analysed with regard to the long-term rather than short-term gains.

\section{Re-negotiate contracts}

The bank should renegotiate its contract with the telecommunications provider to make it more flexible and modern as in strategic alliance and risk-reward type of relationships, to get a better deal for their funds invested.

\section{Good communication between client and vendor} Both parties must agree to communicate effectively to make the outsourcing deal successful for all.

\section{Executive commitment}

Strong executive support by both parties is a strong factor for successful outsourcing in the case studied.

\section{Choice of vendors}

Choose from a broad range of IT vendors, and consider outsourcing carefully when faced with a limited choice of vendors.

\section{Short-term contracts}

Companies outsourcing for the first time must sign shortterm to medium-term contracts with vendors to avoid a 'contractual stranglehold' and to acquire a better understanding of outsourcing and transaction costs.

\section{Analysis of vendor bid proposals}

Analyse vendors' bid proposals to rethink and re-evaluate an in-house provision of the IT service(s) by examining how vendors intend to provide better solutions.

- co-ordination and logistical problems between suppliers leading to intellectual protectionism and knowledge management issues; and

- too much emphasis on commissioning rather than providing a service.

\section{Toward a frame of reference for IT/IS outsourcing}

The findings reported from the case study complement the research reported by Hirschheim and Lacity (2000), who conclude that although cost savings are necessarily part of the outsourcing or insourcing decision-making process, closer analysis reveals that the perceptions that the various stakeholders have of the process are central. These perceptions influence both the decisions made, at various stages, and also the evalation of eventual success or failure. Although their research describes benefits in terms of what is more easily quantifiable, that is, the trade-off between cost and service, Hirshheim and Lacity (2000) conclude that whatever decisions are made, eventual success or failure can be measured only by looking at the stakeholders themselves. It would appear from their text, although they do not state it, that this necessarily involves looking at less easily quantifiable factors, as terms such as 'frustration', 'loss of faith', 'expectations', 'political obstacles', 'freedom' and 'power' abound in their description of the complex interplay between different stakeholders within an organisation (p 107). Given these, and other complexities, key findings are used to develop a frame of reference, which other organisations may use as a guideline for their outsourcing decisionmaking. Given that many unsuccessful outsourcing contracts go unannounced or unpublished, this results in no opportunity for learning from previous outsourcing experiences. With this in mind, and based on the experiences of the case study discussed in this paper, Table 3 offers suggestions that organisations should consider when outsourcing. It should be noted, however, that these should be seen not as prescriptive, but instead as merely descriptive issues for consideration.

Determining the motives, costs, benefits and risks that support the outsourcing decision-making process is complicated. At various stages, and for various reasons, the bank based its decisions on a diverse set of factors influencing what they perceived to be the beneficial outcomes of those decisions. Thus, as noted in Table 4, the following taxonomies for decision-making should be incorporated into an organisation decision-making strategy: economic, technical, political, strategic and organisational.

Despite the generally accepted and conventional view of outsourcing as a cost-controlling strategy, many other motives have emerged with the maturity of the outsourcing market. The experiences of the bank presented in this paper serve as an example to illustrate that organisations outsource to gain a number of benefits not just those that are financial in nature.

\section{Conclusions}

This paper has identified the implicit motives for outsourcing IT/IS functions. The bank's experience is a case 
Table 4 Four categories of motives for outsourcing decisions

\section{Strategic and organisational}

- Focus on core business.

- Eliminate a burdensome IT function.

- Gain access to high quality IT services and skills.

- Reduce a backlog of application development.

- Restructure (devolution of IT), ie downsizing.

- Handle fluctuating IT demands.

- Exploit new technology.

- Market testing.

- Share risks and rewards.

- Speedy response to IT needs.

- Accelerate reengineering benefits.

Political and other reasons

- Government legislation.

- Enhancement of credibility.

- Solve internal conflicts.

- Reaction to the bandwagon.

\section{Technical reasons}

- Access to expertise/technology.

- Perceived poor performance of internal staff.

- Access to better quality services.

\section{Economic}

- Save costs.

- Generate a cash flow.

- Convert capital assets to revenue.

- Accountability of control.

- Free resources for core activities.

- Control IT cost (cost predictability).

of a selective approach to outsourcing, but with a limited range of vendors (at the time) and with an inadequately defined contract. Despite this, most of its objectives for outsourcing were claimed by the banks outsourcing decision-makers to have been realised. The research findings identified that decisions to outsource based on long-term strategic motives need to be looked at very closely, as these are revealed as important in understand- ing how and why outsourcing decisions are carried out. It would appear from the case study that IT/IS outsourcing took place where it is a core business activity, and where senior management has control over the IT/IS functions. In the case of the bank, this allowed management to ensure that their underlying aim to increase competitiveness remained a strategic objective. The bank claimed to have mitigated technological risks and uncertainty, and gained some access to new technology, albeit not as effectively as it had expected. Decisions regarding outsourcing, as the experience from the bank demonstrates, are more complicated than simply a matter of choosing cost savings over more business-wide benefits.

This paper has reviewed and analysed a case study, and in doing so, complemented the normative literature and also made a distinct contribution towards the outsourcing debate. Several factors that influenced the decision-making process other than financial were identified and described. Given the current economic climate, where short-term, selective outsourcing contracts with multiple vendors are becoming more commonplace, this case study serves to highlight the need to focus greater attention on discriminating between the short and longterm consequences of decision-making when faced with risk. As can be seen from the case study, such factors are often not visible and are inextricably linked to the individuals and the structure within an organisation, that is, the organisational culture. Given the level of maturity of the outsourcing market and the fast pace of technological change in IT/IS, this case study, and the resulting terms of reference, serve as a basis for further debate regarding the motives for outsourcing decisions.

Acknowledgements - The authors are most grateful to the four anonymous referees, whose helpful and constructive comments were used to improve this manuscript. Also, the authors would like to express their gratitude to Dr Steve Smithson who made numerous comments and encouraged the completion of this paper. The authors would like to thank the case study company and interviewees. Finally, the authors acknowledge the contribution to this paper from Dominic Benson.

\section{References}

ANTONUCCI YL and TUCKER JJ (1998) IT outsourcing, current trends, benefits, and risks. Information Strategy: the Executive's Journal 14(2), 16-26.

Collins T (1998) Making waves. Computer Weekly 21 May 1998

Cronk J and Sharp J (1995) A framework for deciding what to outsource in IT. Journal of Information Technology 10, 259-267.

CURrie WL (1996) Outsourcing in the private and public sectors: an unpredictable IT strategy. European Journal of Information Systems 4, 226-236.

CURrie WL (1998) Using multiple suppliers to mitigate the risks of IT outsourcing at ICI and Wessex Water. Journal of Information Technology 13(3), 169-180.

Currie WL (2000) The supply-side of IT outsourcing: the trend towards mergers, acquisitions and joint ventures. International Journal of Physical Distribution and Logistics Management, Special Issue on Supporting Supply Chain Management through IT/IS Infrastructure (IrAni Z, Love PED and Li H, Eds), 30(3-4): 238-254.

CURrie WL and Willcocks LP (1997) Analysing four types of IT sourcing decisions: key issues in IS. In Proceedings of the Second UKAIS Conference, pp 133-141, University of Southampton, UK.

DUNCAN NB (1998) Beyond opportunism: a resource-based view of outsourcing risk. In Proceedings of the Thirty-First Annual Hawaii International Conference on System Sciences, VI, pp 675-684, IEEE Computer Society, Los Alamitos, California, US.

FINK D and SHoeib A (1998) A behavioral decision making model for outsourcing IS: matching technology with organisational needs. In Proceedings of the Third UKAIS Conference, pp 287-297, Lincoln University, UK.

FitzGerald G and Willcocks LP (1994) Outsourcing in the UK and vendor/client relationship issues. In Proceedings of the Fifteenth International Conference on Information Systems, pp 91-98, Canada.

Fowler A and JeFFs B (1998) Examining information systems outsourcing: a case study from the United Kingdom. Journal of Information Technology 13(2), 111-126.

HirschHeIM R and LACITY M (2000) The myths and realities of infor- 
mation technology insourcing. Communications of the ACM 43(2), 99-107.

INTERNATIONAL DATA CORPORATION (1998) European Outsourcing Markets and Trends, 1995-2001. IDC, London, UK.

JICK TD (1979) Mixing qualitative and quantitative methods: triangulation in accumulation. Administrative Science Quarterly 24602 611.

Ketler K and Walstrom J (1993) Outsourcing decisions. International Journal of Information Management 13(6), 449-459.

LACITY MC and HiRsCHHEIM R (1993) The information systems outsourcing bandwagon. Sloan Management Review 35(1), 73-86.

LACITY MC and WillCocks LP (1998) An empirical investigation of Information Technology sourcing practices: lessons from experience. MIS Quarterly 22(3), 363-393.

LOH L and Venkatraman N (1992) Determinants of information technology outsourcing. Journal of Management Information Systems 9(1), 7-24.

Marcolin B and McClennan K (1998) Effective IT outsourcing arrangements. In Proceedings of the Thirty-First Annual Hawaii Computer Society, Los Alamitos, California, US.

NGwenyama OK and Bryson N (1999) Making the information sysInternational Conference on System Sciences, VI, pp 654-665, IEEE

tems outsourcing decision: a transaction cost approach to outsourcing decision problems. European Journal of Operational Research 114, 351-367.

O'BRIEN JA (1996) Management Information Systems: Managing Information in the Networked Enterprise, third edition. Irwin, US.

QuinN JB (1999) Strategic outsourcing. Sloan Management Review 40(4), 23-26.

Quinn JB and Hilmer FG (1994) Strategic outsourcing. Sloan Management Review 35(4), 43-55.

SCHOEMAKER PJH (1995) Scenario planning: a tool for strategic thinking. Sloan Management Review 36(2), 25-40.

WEICK KE (1984) Theoretical assumptions and research methodology selection. In The Information Systems Research Challenge (McFarlan FW, Ed), pp 111-132, Harvard Business School, US.

WILlCOCKS LP and KERN T (1998) IT outsourcing as strategic partnering: the case of the UK Inland Revenue. European Journal of Information Systems 7(1), 29-45.

YANG C and HuANG JB (2000) A decision model for IS outsourcing. International Journal of Information Management 20(1), 225-239.

YIN RK (1994) Case Study Research: Design and Methods. Applied Social Research Methods Series, Volume 5, Sage Publications, US.

the editorial advisor board of several journals, as well as being co-and-mini-track chair to international conferences. He has guest edited special issue journals that include: IEEE Transactions, European Journal of Information Systems, International Journal of Technology Management, Information Systems Journal. Dr Irani has received numerous grants and awards from national/international funding bodies: Engineering and Physical Sciences Research Council (EPSRC), Royal Academy of Engineering, Australian Research Council (ARC), Defence Evaluation Research Agency (DERA) and European Commission (EC). Further details are available at: http://www.brunel.ac.uk/ csstzni/

Dr Zahir Irani is a Senior Lecturer in the Department of Information Systems and Computing, Brunel University (UK). Having worked for several years as a project manager, Zahir retains close links with industry, and is a non-executive director to a leading 'blue-chip' company, and consults with organisations such as Shell Petroleum, Glaxo Wellcome, BMW (UK) and Adidas. Dr Irani also evaluates European Commission (EC) ESPRIT research proposals that are submitted as part of the fifth framework. Dr Irani serves as a non-executive member to an international academic advisory group for MCB University Press, and is a member of the editorial board of Butterworth Heinemann/Computer Weekly - Professional Information Systems Text Books series.

Dr Irani leads a multidisciplinary group of researchers in the area of information systems evaluation and integration. $\mathrm{He}$ is a Visiting Scholar to the University of Salford (UK) and a Visiting Professor at Deakin University (Australia). Dr Zahir Irani is the Editor in Chief of the journal of Logistics and Information Management, and has co-authored a teaching textbook on information systems evaluation, and written over 100 internationally refereed papers. He has presented at conferences world wide, and is internationally known for his scholarly work in the area of information systems evaluation. Dr Irani is on
Peter ED Love is an Associate Professor and Director of the Australian Agile Construction Initiative. He has co-authored two books, written over 100 internationally refereed journals and spoken at conferences worldwide in the areas of quality and IT/IS project management. Evidence of his output can be found in numerous international journals, such as: European Journal of Information Systems, International Journal of Production Economics, and International Journal of Information Management. In addition, he has guest edited special issue international journals on the themes of Multimedia Technology, Electronic and Internet Commerce and Supporting Supply Chains through IT/IS. Professor Love evaluates grant proposals submitted to the Engineering and Physical Sciences Research Council (EPSRC) in the UK. His research in the area of IT/IS has been recognised by the Department of Building and Real Estate at Hong Kong Polytechnic University, as he has been invited on several occasions to attend the department as a Visiting Professor. He also serves on the Editorial Advisory Board of several international journals and conference scientific technical committees. 